\title{
Chemical Composition and Antioxidant Activity of Euterpe oleracea Roots and Leaflets
}

\author{
Christel Brunschwig ${ }^{\dagger}$, Louis-Jérôme Leba ${ }^{\dagger}$, Mona Saout, Karine Martial, Didier Bereau and \\ Jean-Charles Robinson * \\ UMR QUALITROP, Université de Guyane, Campus Universitaire de Troubiran, P.O. Box 792, 97337 Cayenne \\ Cedex, French Guiana, France; christel.brunschwig@gmail.com (C.B.); louis-jerome.leba@univ-guyane.fr (L.-J.L.); \\ mona.saout@gmail.com (M.S.); karine.martial@univ-guyane.fr (K.M.); didier.bereau@univ-guyane.fr (D.B.) \\ * Correspondence: jean-charles.robinson@univ-guyane.fr; Tel.: +594-594-29-99-46 \\ † These authors contributed equally to this work.
}

Academic Editor: Toshio Morikawa

Received: 27 October 2016; Accepted: 12 December 2016; Published: 29 December 2016

\begin{abstract}
Euterpe oleracea (açaí) is a palm tree well known for the high antioxidant activity of its berries used as dietary supplements. Little is known about the biological activity and the composition of its vegetative organs. The objective of this study was to investigate the antioxidant activity of root and leaflet extracts of Euterpe oleracea (E. oleracea) and characterize their phytochemicals. E. oleracea roots and leaflets extracts were screened in different chemical antioxidant assays (DPPH-2,2-diphenyl-1-picrylhydrazyl, FRAP—ferric feducing antioxidant power, and ORAC—oxygen radical absorbance capacity), in a DNA nicking assay and in a cellular antioxidant activity assay. Their polyphenolic profiles were determined by UV and LC-MS/MS. E. oleracea leaflets had higher antioxidant activity than E. oleracea berries, and leaflets of Oenocarpus bacaba and Oenocarpus bataua, as well as similar antioxidant activity to green tea. E. oleracea leaflet extracts were more complex than root extracts, with fourteen compounds, including caffeoylquinic acids and $C$-glycosyl derivatives of apigenin and luteolin. In the roots, six caffeoylquinic and caffeoylshikimic acids were identified. Qualitative compositions of E. oleracea, Oenocarpus bacaba and Oenocarpus bataua leaflets were quite similar, whereas the quantitative compositions were quite different. These results provide new prospects for the valorization of roots and leaflets of E. oleracea in the pharmaceutical, food or cosmetic industry, as they are currently by-products of the açaí industry.
\end{abstract}

Keywords: Euterpe oleracea; açaí; antioxidant activity

\section{Introduction}

Euterpe oleracea (E. oleracea), known as açaí worldwide and wassaye in French Guiana, is a palm tree native from the Amazonian rainforest, which gives purple berries with high potential currently used as dietary food supplements or in cosmetics thanks to their high antioxidant activity. Traditionally, açaí berries are consumed as a beverage called "açaí vino" in Brazil. Since the mid 2000s, many scientific studies focused on E. oleracea berries due to its biological activities including anti-proliferative, anti-inflammatory, antioxidant, and cardioprotective properties. E. oleracea was also found to be extremely rich in antioxidant compounds including phenolic acids, flavonoids and anthocyanins [1,2].

While açaí berries are mainly used as foodstuffs, E. oleracea vegetative organs (such as leaves and roots) are traditionally used in medicine, curing snake bites [3], diabetes, kidney and liver pains, fever, anemia, as well as arthritis, or used as hemostatic [4,5]. Roots of Euterpe precatoria, a close species to E. oleracea, also showed anti-inflammatory [6] and antioxidant properties [7]. The vegetative organs of E. oleracea are considered as waste from the açaí palm heart industry and could be potential sources of 
phytochemicals with cosmetic, pharmaceutical or nutritional applications. Currently, there is interest in valorizing polyphenols-containing food wastes such as grape skins, olive mill waste water, citrus peels, seed wastes or berry leaves [8,9] as there is a growing demand for polyphenols for pharmaceutical, cosmetic and food industries, especially to treat cardiovascular, and skin diseases, cancer, aging, and diet issues. Some studies have already been carried out on açaí seeds, another waste from the açaí industry. Antioxidant activity [10] and anti-nociceptive activity have been demonstrated [11], showing that this waste could find applications in the food or pharmaceutical industries. Therefore, there is also a real value in enhancing the knowledge of the phytochemical composition and pharmacological activities of açaí roots and leaves. A previous study showed that roots and leaflets of two other Amazonian palm trees (Oenocarpus bacaba and Oenocarpus bataua) had high antioxidant activity, underlining both Oenocarpus vegetative organs as good sources of antioxidant compounds [12]. In this paper, we therefore investigated the antioxidant activity of root and leaflet crude extracts of E. oleracea using different chemical antioxidant assays (DPPH-2,2-diphenyl-1-picrylhydrazyl, FRAP—ferric reducing antioxidant power, and ORAC—oxygen radical absorbance capacity), a DNA nicking assay and a cellular antioxidant activity assay, while LC-MS/MS was performed to elucidate the structures of the bioactive compounds.

\section{Results and Discussion}

\subsection{Antioxidant Activity}

\subsubsection{Antioxidant Activity in the Chemical Assays (DPPH, FRAP, and ORAC)}

Antioxidant properties of root and leaflet extracts from E. oleracea were investigated using different chemical assays (DPPH, FRAP and ORAC) having different modes of action: hydrogen transfer (ORAC), electron transfer (FRAP) or a mixed mode (DPPH) [13]. In all antioxidant tests, best results were obtained for acetone extracts independently of the organ used. Leaflet extracts were more active than root extracts, independently of the solvent used.

In the DPPH assay, values for E. oleracea leaflet extracts ranged from 480 to $990 \mu \mathrm{mol}$ Trolox $\mathrm{Eq} / \mathrm{g}$ Dry Matter ( $\mu \mathrm{mol} \mathrm{TEq} / \mathrm{g} \mathrm{DM})$. DPPH activity of E. oleracea acetone leaflet extracts were at least two-fold higher than E. oleracea and O. bataua berries [14], two-fold higher than Oenocarpus leaflets acetone extracts [12], and slightly lower than green tea $(1200 \mu \mathrm{mol} \mathrm{TEq} / \mathrm{g}$ DM) (Table 1).

In the FRAP assay, all values for leaflet extracts ranged from 1000 to $1400 \mu \mathrm{mol} F e(\mathrm{II}) \mathrm{Eq} / \mathrm{g}$ DM. They were two-fold higher than palm berries [14-16], at least two-fold higher than antioxidant foodstuffs like lettuce [17], but lower than green tea extracts (1900-2700 $\mu \mathrm{mol} \mathrm{Fe(II)Eq/g} \mathrm{DM)} \mathrm{(Table} \mathrm{1).}$ When comparing leaflet acetone extracts, E. oleracea FRAP activity was two-fold higher than O. bataua and similar to O. bacaba [12].

The ORAC assay, considered as one of the most relevant amongst antioxidant chemical assays, gave ORAC values from 1600 to $2200 \mu \mathrm{mol} \mathrm{TEq} / \mathrm{g}$ DM, for leaflet extracts. They were at least three-fold more active than palm berries in the ORAC assay [14], at least 1.5-fold more active than the best Oenocarpus leaflet extracts [12] and almost equivalent to green tea with $2400 \mu \mathrm{mol} \mathrm{TEq} / \mathrm{g}$ DM (Table 1). Besides, even if E. oleracea roots were less active than E. oleracea leaflets in all the antioxidant tests, their activities were as high or higher than those of E. oleracea and O. bataua berries, as illustrated by ORAC results (300-1300 $\mu \mathrm{mol} \mathrm{TEq/g} \mathrm{DM)} \mathrm{(Table} \mathrm{1).}$

Root and leaflet extracts from E. oleracea were active across the board in the different chemical antioxidant assays (DPPH, FRAP, and ORAC) showing that they act according to different mechanisms of action such as electron and/or hydrogen transfer. Root and leaflet extracts were at least as active as palm berries, considered as super fruits. Leaflet extracts were the most antioxidant extracts, almost equivalent to green tea leaves, which have one of the strongest recorded antioxidant activity. 
Table 1. Antioxidant activity and total phenolic content (TPC) of root and leaflet extracts of Euterpe oleracea.

\begin{tabular}{|c|c|c|c|c|c|c|}
\hline $\begin{array}{c}\text { Extract Name } \\
\text { (Plant/Part/Solvent) }\end{array}$ & $\begin{array}{c}\text { TPC ( } \mu \mathrm{g} \\
\text { GAEq/mg DM) * }\end{array}$ & $\begin{array}{l}\text { DPPH }(\mu \mathrm{mol} \\
\text { TEq/g DM) }\end{array}$ & $\begin{array}{c}\text { FRAP }(\mu \mathrm{mol} F e(I I) \\
\text { Eq/g DM) }\end{array}$ & $\begin{array}{l}\text { ORAC }(\mu \mathrm{mol} \\
\text { TEq/g DM)* }\end{array}$ & $\underset{(\mu \mathrm{g} / \mathrm{mL})}{\mathrm{EC}_{50} \text { in NHDF }}$ & $\begin{array}{c}\text { CAA in NHDF } \\
(\mu \mathrm{mole} Q \mathrm{QEq} / \mathrm{g} \text { DM })\end{array}$ \\
\hline WRA & $58 \pm 9^{b, c}$ & $471 \pm 101^{b}$ & $769 \pm 137^{\mathrm{c}, \mathrm{d}}$ & $1259 \pm 320^{c}$ & $14 \pm 2$ & $29 \pm 4$ \\
\hline WLW & $62 \pm 7^{a, b}$ & $479 \pm 39 b, c$ & $965 \pm 178^{b, c}$ & $1643 \pm 385^{b, c}$ & $29 \pm 9$ & $45 \pm 12$ \\
\hline WLA & $84 \pm 7^{a}$ & $991 \pm 81^{\mathrm{a}}$ & $1381 \pm 376^{\text {a }}$ & $2229 \pm 484^{a}$ & $10 \pm 1$ & $208 \pm 23$ \\
\hline WLM & $76 \pm 7^{\mathrm{a}, \mathrm{b}}$ & $660 \pm 72^{b}$ & $1194 \pm 180^{\mathrm{a}, \mathrm{b}}$ & $2177 \pm 611^{\mathrm{a}, \mathrm{b}}$ & $16 \pm 2$ & $87 \pm 12$ \\
\hline TLW $^{\mathrm{e}}$ & $100 \pm 9$ & $748 \pm 52$ & $1911 \pm 82$ & $1348 \pm 45$ & - & - \\
\hline ObcLA $^{f}$ & 60 & 540 & 1030 & 1560 & 24 & 50 \\
\hline ObcBA $g$ & 30 & 240 & 200 & 170 & - & - \\
\hline WBA ${ }^{g}$ & 40 & 240 & 130 & 430 & - & - \\
\hline
\end{tabular}

${ }^{*}$ Averages with the same letter ${ }^{\mathrm{a}-\mathrm{d}}$ within columns are not significantly different $(p<0.05)$ using Fisher's Least Significant Difference test; W: Wassaye (E. oleracea); Obt: O. bataua; Obc: O. bacaba; R: roots; L: leaflets; B: berries; T: Green Tea leaves; W: water; A: acetone/water 70/30; M: methanol/water 70/30; CAA: cellular antioxidant activity; NHDF: normal human dermal fibroblasts; GAEq: Gallic acid equivalent; TEq: Trolox equivalent; QEq: Quercetin equivalent; DM: dry matter; TPC: total phenolic content; $\mathrm{EC}_{50}$ : median effective concentration; CAA: cellular antioxidant activity; DPPH: 2,2-Diphenyl-1-picrylhydrazyl; FRAP: ferric reducing antioxidant power; ORAC: oxygen radical absorbance capacity; ${ }^{\mathrm{e}}$ data from Leba et al., 2014 [16]; ${ }^{\mathrm{f}}$ data from Leba et al., 2016 [12]; $\mathrm{g}$ data from Rezaire et al., [14].

\subsubsection{Antioxidant Activity in the DNA Nicking Assay}

Despite optimization of the DNA nicking assay conditions, the sensitivity using methanol extracts was low [16], therefore only aqueous and acetone extracts of E. oleracea were assessed in the DNA nicking assay. All root extracts of E. oleracea were found to be active in this assay. The aqueous and acetone root extracts had an antioxidant effect at all concentrations tested; they protected form I from degradation and reduced the formation of linear nicked form III in a similar way to Trolox at $1 \mathrm{mg} / \mathrm{mL}$ (Figure 1). Aqueous leaflet extracts had an antioxidant effect in the DNA nicking assay at all concentrations tested $(1 \mathrm{mg} / \mathrm{mL}$ and $10 \mathrm{mg} / \mathrm{mL})$, while acetone leaflet extracts had an antioxidant effect at $10 \mathrm{mg} / \mathrm{mL}$ and a prooxidant effect at a lower concentration of $1 \mathrm{mg} / \mathrm{mL}$. The overall high potency of the root and leaflet extracts of E. oleracea in the DNA nicking assay encouraged the evaluation of their antioxidant activity in an assay physiologically more relevant, i.e., a cell-based antioxidant assay.

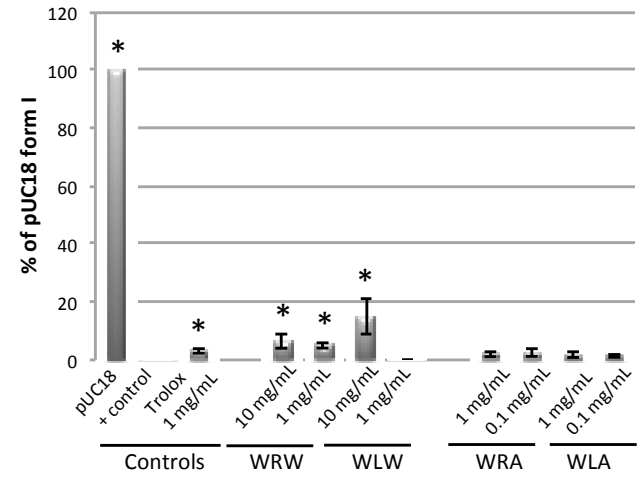

(a)

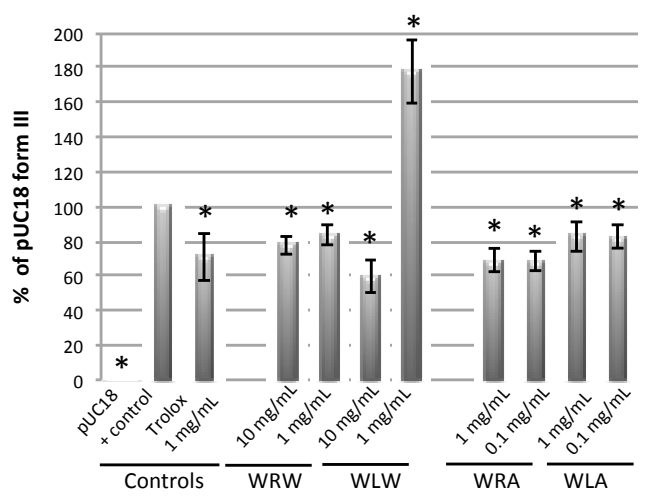

(b)

Figure 1. Antioxidant activity of Euterpe oleracea extracts in the DNA nicking assay indicating: (a) protection of supercoiled form I; and (b) formation of nicked linear form III; W: Wassaye (E. oleracea); R: roots; L: leaflets; W: water; A: acetone/water 70/30; $\left.{ }^{*} p<0.05 ; n=3\right)$. 


\subsubsection{Cytotoxicity and Cellular Antioxidant Activity (CAA)}

As root and leaflet extracts of E. oleracea were not cytotoxic to normal human dermal fibroblasts (NHDF) at $100 \mu \mathrm{g} / \mathrm{mL}$ in the MTT (3-(4,5-dimethylthiazol-2-yl)-2,5-diphenyltetrazolium bromide) assay (Table S1), they were tested at this concentration in the Cellular Antioxidant Activity (CAA) assay.

Root and leaflet extracts from E. oleracea were quite active in the cellular antioxidant assay with the median effective concentration $\left(\mathrm{EC}_{50}\right.$ ) ranging from 10 to $30 \mu \mathrm{g} / \mathrm{mL}$ (Table 1). Most of the palm extracts were more active than fruits including kiwis, blueberries, carrots and strawberries, which had a high antioxidant activity ( $\mathrm{EC}_{50}$ from 50 to $200 \mu \mathrm{g} / \mathrm{mL}$ ) in a similar cell-based assay [18].

Leaflet extracts of E. oleracea were more active in the CAA assay (45-208 $\mu \mathrm{mol}$ Quercetin Eq/g $\mathrm{DM})$ than root extracts (10-30 $\mu \mathrm{mol}$ Quercetin Eq/g DM) and acetone extracts were more active than methanol extracts. Activities for E. oleracea were quite similar to Oenocarpus roots (10-50 $\mu \mathrm{mol}$ Quercetin Eq/g DM), whereas E. oleracea leaflets were at least two-fold superior than Oenocarpus leaflets (7-100 $\mu \mathrm{mol}$ Quercetin Eq/g DM) [12]. Interestingly, there was a very high correlation between the ORA activity and the cell-based activity (Pearson's r correlation coefficients of 0.976) (Figure S1), which are both based on the ROO- radical scavenging capacity of the extracts. These correlations were also found in the work of Girard-Lalancette et al., 2009 and Leba et al., 2016 [12,18]. The high potency of extracts in the ORAC assay translated well in the CAA assay, meaning that compounds were able to act in a cellular environment, either by crossing membrane cells or by directly scavenging radicals outside the cells. These results encourage investigating the chemical composition of E. oleracea root and leaflet extracts.

\subsection{Total Phenolic Content (TPC)}

The Total Phenolic Content (TPC) of root and leaflet extracts from E. oleracea ranged from 14 to $84 \mu \mathrm{g}$ Gallic acid equivalent/mg Dry Matter ( $\mu \mathrm{g}$ GAEq/mg DM) (Table 1).

Best results were found with acetone independently of the organ used. The highest values were found for the leaflet extracts of E. oleracea, with $84 \mu \mathrm{g}$ GAEq/mg DM, which was two-fold higher than the TPC of palm berries including E. oleracea, O. bataua [14] and O. bacaba [15], known to be antioxidants. The TPC of E. oleracea roots were globally similar to that of Oenocarpus roots extracts [12], whereas E. oleracea leaflets were richer in polyphenols than Oenocarpus leaflets [12]. Moreover, the TPC of E. oleracea leaflets was almost similar to the TPC of green tea leaves (100-125 $\mu \mathrm{g} \mathrm{GAEq} / \mathrm{mg}$ ), which has one of the strongest recorded antioxidant activities. There was a high correlation between the total polyphenolic content (TPC) and the antioxidant activity in the different assays $(p<0.05)$ with high Pearson's r correlation coefficients between TPC and DPPH (0.945), TPC and FRAP (0.983), TPC and ORAC (0.986), and TPC and CAA activity (0.968) (Figure S1).

\subsection{Identification of Compounds in Root and Leaflet Extracts by LC-MS/MS}

The UV chromatograms recorded at $320 \mathrm{~nm}$ showed that both E. oleracea root and leaflet extracts (Figure 2) contained polyphenols, whose structures (Figure 3) were then determined by LC-MS/MS. Leaflet extracts showed more complex polyphenol profiles (fourteen compounds) than root extracts (six compounds), while some peaks $(\mathbf{1}, \mathbf{2}$, and $\mathbf{3})$ were common to both extracts. 


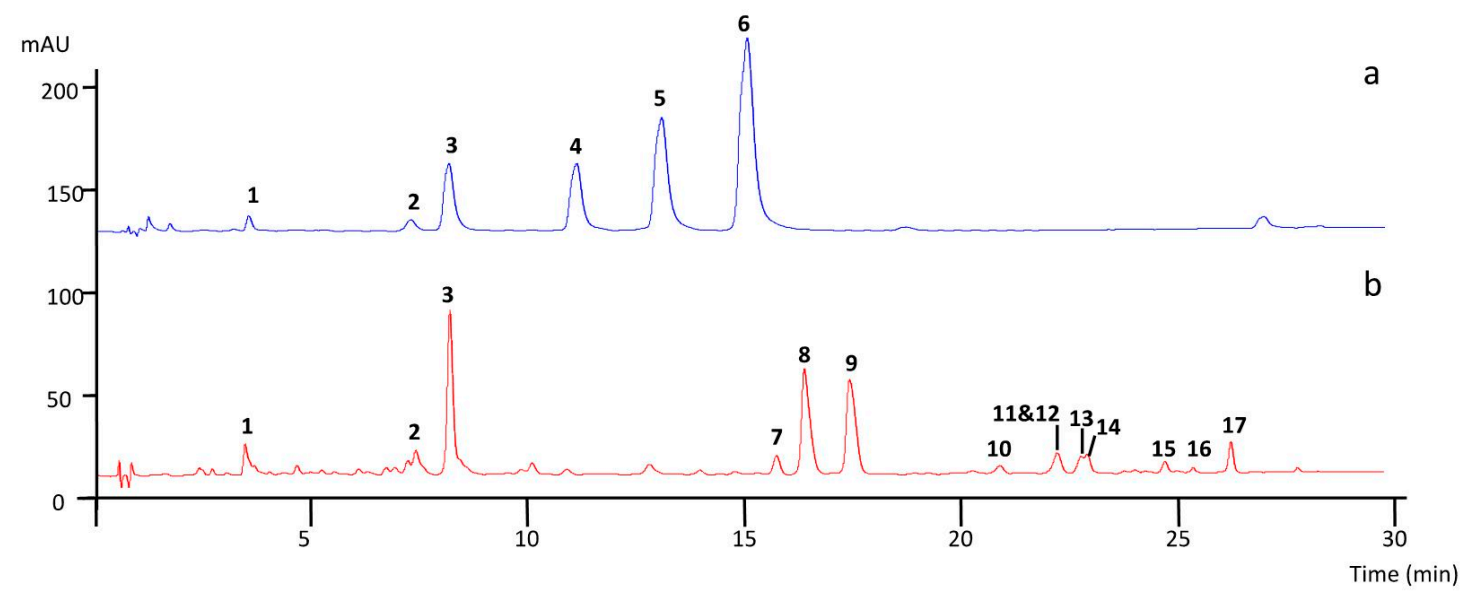

Figure 2. Representative chromatograms of: (a) root extracts; and (b) leaflet extracts of Euterpe oleracea at $\lambda=320 \mathrm{~nm}$; Kinetex PFP column $100 \times 4.6 \mathrm{~mm}, 2.6 \mu \mathrm{m}$; (1) 3-CQA; (2) 4-CQA; (3) 5-CQA; (4) 4-CSA; (5) 5-CSA; (6) CSA; (7) 6,8-di-C-hexosyl apigenin; (8,9) 6,8-di-C-hexosyl apigenin sulfate; $(\mathbf{1 0 , 1 4 , 1 5 )}$ 6-C-hexosyl-8-C-pentosyl apigenin isomers; $(\mathbf{1 2 , 1 6 )} 6-C$-pentosyl-8- $C$-hexosyl apigenin isomer; (11) 8-C-glucosyl luteolin; (13) 6-C-glucosyl luteolin; and (17) 6-C-glucosyl apigenin; CQA: caffeoylquinic acid; CSA: caffeoylshikimic acid.

\section{Hydroxycinnamic acids}

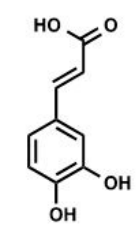

Caffeic acid Caff

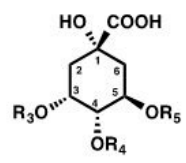

Quinic acid Q

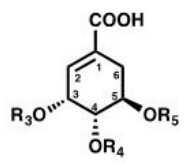

Shimikic acid S<smiles>O=C(/C=C/c1ccc(O)c(O)c1)O[C@@H]1C[C@@](O)(C(=O)O)C[C@H](O)[C@H]1O</smiles>

3-O-caffeoylquinic acid<smiles>O=C(/C=C/c1ccc(O)c(O)c1)O[C@@H]1CC(C(=O)O)=C[C@H](O)[C@@H]1O</smiles>

5-O-caffeoylshikimic acid

\begin{tabular}{llll} 
Compound & $\mathrm{R}_{3}$ & $\mathrm{R}_{4}$ & $\mathrm{R}_{5}$ \\
\hline 3-O-caffeoylquinic acid & Caff & $\mathrm{H}$ & $\mathrm{H}$ \\
4-O-caffeoylquinic acid & $\mathrm{H}$ & Caff & $\mathrm{H}$ \\
5-O-caffeoylquinic acid & $\mathrm{H}$ & $\mathrm{H}$ & Caff
\end{tabular}

\begin{tabular}{llll} 
Compound & $\mathrm{R}_{3}$ & $\mathrm{R}_{4}$ & $\mathrm{R}_{5}$ \\
\hline 3-O-caffeoylshikimic acid & $\mathrm{Caff}$ & $\mathrm{H}$ & $\mathrm{H}$ \\
4-O-caffeoylshikimic acid & $\mathrm{H}$ & Caff & $\mathrm{H}$
\end{tabular}

5-O-caffeoylshikimic acid $\quad \mathrm{H} \quad \mathrm{H} \quad$ Caff

\section{Flavones}

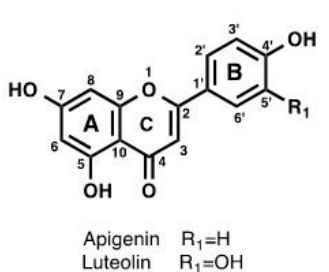<smiles>[B]c1cc(-c2cc(=O)c3c(O)cc(O)c(Cl)c3o2)ccc1O</smiles>

Apigenin 8-C-glucoside $\mathrm{R}_{1}=\mathrm{H}$ Luteolin 8-C-glucoside $\mathrm{R}_{1}=\mathrm{OH}$<smiles>[B]c1cc(-c2cc(=O)c3c(O)c(Cl)c(O)cc3o2)ccc1O</smiles>

Apigenin 6-C-glucoside $\mathrm{R}_{1}=\mathrm{H}$ $\begin{array}{ll}\text { Apigenin 6-C-glucoside } & \mathrm{R}_{1}=\mathrm{H} \\ \text { Luteolin 6-C-glucoside } & \mathrm{R}_{1}=\mathrm{OH}\end{array}$

Figure 3. Structure of main components of root and leaflet extracts of Euterpe oleracea; Glc: glucose.

\subsubsection{Characterization of Caffeoylquinic Derivatives $(M r=354)$ in Root and Leaflet Extracts}

In the root and leaflet extracts, three peaks $(\mathbf{1}, \mathbf{2}$, and 3$)$ at retention time $\left(t_{\mathrm{R}}\right) 4.2,7.2$ and $9.1 \mathrm{~min}$ yielded $[\mathrm{M}-\mathrm{H}]^{-}$ions at $m / z 353$ and $[\mathrm{M}+\mathrm{Na}]^{+}$at $m / z 377$ and showed UV spectra (at $\lambda=298 \mathrm{~nm}$ and $320 \mathrm{~nm}$ ) characteristic of caffeoylquinic acids (CQA, $\mathrm{Mr}=354)$.

In positive mode, the ions at $m / z 163$ and 145, produced by the loss of the quinic acid moiety [19] were not conclusive of the structure of the CQA. The structure of CQA isomers was assigned according 
to their diagnostic ions at $m / z 191,179$ and 173 in the negative mode [20]. Compound $2\left(t_{\mathrm{R}} 7.2 \mathrm{~min}\right)$ was assigned to 4-CQA, having a base peak at $m / z 173$ in the MS ${ }^{2}$ spectrum. Compounds $1\left(t_{\mathrm{R}} 4.2 \mathrm{~min}\right)$ and $3\left(t_{\mathrm{R}} 9.1 \mathrm{~min}\right)$, both having $m / z 191$ as a base peak were distinguished by the intense ion at $m / z 179$ in the $\mathrm{MS}^{2}$ spectrum, characteristic of 3-CQA for compound 1, whereas compound 3 was assigned to 5-CQA (Table 2). The retention order of the CQA isomers $(3<4<5)$ was similar to the study of Regos and Treutter, 2010 [21] using a similar PFP column.

\subsubsection{Characterization of Caffeoylshikimic Derivatives $(\mathrm{Mr}=336)$ in Root Extracts}

In the root extracts, three peaks $(4,5,6)$ at $t_{\mathrm{R}} 12.2,14.2$ and $16.2 \mathrm{~min}$ yielded $[\mathrm{M}-\mathrm{H}]^{-}$ions at $m / z 335,[\mathrm{M}+\mathrm{Na}]^{+}$at $m / z 359$, and showed UV spectra $(\lambda=298 \mathrm{~nm}$ and $320 \mathrm{~nm})$ corresponding to caffeoylshikimic acids (CSA, $M r=336)$. In positive mode, the ions at $m / z 163$ and 145 were characteristic of the caffeoyl moiety [19]. The structure of CSA was tentatively assigned according to their diagnostic ions at $m / z$ 317, 291, 179, 161 and 135 in negative mode [22-24] (Table 2). The fragmentation pattern of compound 4 with an intense ion at $m / z 161$ was conclusive of a 4-CSA. The absence of the ion at $m / z 161$ in the MS ${ }^{2}$ spectrum of compound 5 and the presence of ions at $m / z 317$ and $m / z 291$ was indicative of a 5-CSA isomer. The fragmentation pattern of compound 6 was close to that of a 4-CSA isomer but was not conclusive of the structure.

\subsubsection{Characterization of Apigenin Derivatives $(\mathrm{Mr}=432, \mathrm{Mr}=594, \mathrm{Mr}=674$, and $\mathrm{Mr}=564)$ in Leaflet Extracts}

The UV spectra of eleven compounds (7-17) in the leaflet extracts of E. oleracea showing a $\lambda_{\max }$ at $340 \mathrm{~nm}$ were indicative of flavone derivatives. Compound $17(\mathrm{Mr}=432)$ gave $[\mathrm{M}-\mathrm{H}]^{-}$at $m / z$ 431 and $[\mathrm{M}+\mathrm{H}]^{+}$at $m / z$ 433. Characteristic losses of 90,120 and $150 \mathrm{Da}$ were diagnostic of hexose residues. The fragment ions at $m / z 311$ (aglycone +42 ) and $m / z 341$ (aglycone +72 ) in negative mode clearly indicate 6-C-glycosyl apigenin [25], whose identity was confirmed with a synthetic standard. Nine compounds, i.e., compounds $7(\mathrm{Mr}=594), 8,9(\mathrm{Mr}=674)$ 10, 12, 14, 15, and $16(\mathrm{Mr}=564)$, showed the characteristic $\mathrm{MS}^{2}$ fragmentation of di-C-glycosyl flavones, the occurrence of fragment ions at $m / z 353$ (aglycone +83 ) and 383 (aglycone +113 ) being indicative of apigenin derivatives [25]. Compound $7(\mathrm{Mr}=594)$ yielded $[\mathrm{M}-\mathrm{H}]^{-}$at $m / z 593$, with a fragmentation pattern in negative mode characteristic of hexose derivatives (losses of $90 \mathrm{Da}$ and $120 \mathrm{Da}$ ) and was assigned to a 6,8-di-C-hexosyl apigenin. Compounds 8 and $9(\mathrm{Mr}=674)$ yielded $[\mathrm{M}-\mathrm{H}]^{-}$at $m / z 673$ and $[\mathrm{M}+\mathrm{K}]^{+}$at 713 . The $\mathrm{MS}^{2}$ spectrum showed a first loss of $80 \mathrm{Da}$, characteristic of sulfates, followed by successive losses of $90 \mathrm{Da}, 120 \mathrm{Da}$ and $150 \mathrm{Da}$, characteristics of hexose residues in both positive and negative modes. Compounds 8 and 9 were tentatively assigned to 6,8-di-C-hexosyl apigenin sulfates. The lack of a hypsochromic shift in the band I of 8 and $\mathbf{9}$ compared to compound 7 suggest the sulfation occurred on position 7 or on the sugar moieties [26]. Six peaks $(\mathbf{1 0}, \mathbf{1 2}, \mathbf{1 4}, \mathbf{1 5}, \mathbf{1 6})(\mathrm{Mr}=564)$ at $t_{\mathrm{R}} 21.2,22.3$, 23.2, 24.9 and $25.6 \mathrm{~min}$ yielded $[\mathrm{M}-\mathrm{H}]^{-}$ions at $m / z 563$ in the negative mode. Their $\mathrm{MS}^{2}$ spectrum showed losses of $60 \mathrm{Da}, 90 \mathrm{Da}, 120 \mathrm{Da}$ and $150 \mathrm{Da}$, characteristic of pentose and hexose residues. They were assigned as 6,8-di-C-pentosyl-hexosyl apigenin derivatives. The $[\mathrm{M}-\mathrm{H}-60]^{-}$ion resulting from the fragmentation of the pentose moiety was more intense in $12(100 \%)$ and $16(25 \%)$ than in other compounds, indicating that the pentose moiety was on position 6 , which fragments preferentially over sugars on position 8 [25]. Therefore, compounds 12 and 16 were identified as 6-C-pentosyl-8-C-hexosyl apigenin isomers. The others compounds $(\mathbf{1 0}, \mathbf{1 4}$, and 15) were assigned as 6-C-hexosyl-8-C-pentosyl apigenin isomers. 
Table 2. Identification of main components of root and leaflet extracts of Euterpe oleracea.

\begin{tabular}{|c|c|c|c|c|c|c|c|c|c|}
\hline$N$ & $t_{\mathrm{R}}(\min )$ & $\mathrm{UV} \lambda_{\max }(\mathrm{nm})$ & Negative Mode MS & Negative Mode MS ${ }^{2}(\%)$ & Positive Mode MS & Positive Mode MS $2(\%)$ & Tentative Identity & Abbreviation & Extracts \\
\hline 1 & 4.2 & $238,295 \mathrm{sh}, 321$ & $353[\mathrm{M}-\mathrm{H}]^{-}$ & $\mathrm{MS}^{2}[353]: 191(100), 179(25)$ & $377[\mathrm{M}+\mathrm{Na}]^{+}$ & $377 / 353 / 163 / 145$ & 3-Caffeoylquinic acid & 3-CQA & Roots, leaflets \\
\hline 2 & 7.9 & $237,286 \mathrm{sh}, 322$ & $353[\mathrm{M}-\mathrm{H}]^{-}$ & $\mathrm{MS}^{2}$ [353]: $173(100)$ & $377[\mathrm{M}+\mathrm{Na}]^{+}$ & $377 / 353 / 163 / 145$ & 4-Caffeoylquinic acid & 4-CQA & Roots, leaflets \\
\hline 3 & 9.1 & $239,295 \mathrm{sh}, 323$ & $353[\mathrm{M}-\mathrm{H}]^{-}$ & $\mathrm{MS}^{2}$ [353]: 191 (100) & $377[\mathrm{M}+\mathrm{Na}]^{+}$ & $377 / 353 / 163 / 145$ & 5-Caffeoylquinic acid & 5-CQA & Roots, leaflets \\
\hline 4 & 12.2 & $239,295 \mathrm{sh}, 325$ & $335[\mathrm{M}-\mathrm{H}]^{-}$ & $\begin{array}{l}\operatorname{MS}^{2}[335]: 291(100), 179(60), \\
161(80), 135(75)\end{array}$ & $359[\mathrm{M}+\mathrm{Na}]^{+}$ & $359 / 163 / 145$ & 4-Caffeoylshikimic acid & 4-CSA & Roots \\
\hline 5 & 14.2 & $239,295 \mathrm{sh}, 325$ & $335[\mathrm{M}-\mathrm{H}]^{-}$ & $\mathrm{MS}^{2}[335]: 317$ (100), 291 (100), $179(50)$ & $359[\mathrm{M}+\mathrm{Na}]^{+}$ & $359 / 163 / 145$ & 5-Caffeoylshikimic acid & 5-CSA & Roots \\
\hline 6 & 16.2 & $239,295 \mathrm{sh}, 325$ & $335[\mathrm{M}-\mathrm{H}]^{-}$ & $\begin{array}{l}\mathrm{MS}^{2}[3355): 317(5), 291(5), 179(75), \\
161(100), 135(80)\end{array}$ & $359[\mathrm{M}+\mathrm{Na}]^{+}$ & $359 / 163 / 145$ & Caffeoylshikimic acid & CSA & Roots \\
\hline 7 & 16.1 & $239,270,335$ & $593[\mathrm{M}-\mathrm{H}]^{-}$ & $\mathrm{MS}^{2}$ [593]: 503 (20), 473 (25), $383(50), 353(50)$ & $595[\mathrm{M}+\mathrm{Na}]^{+}$ & $595 / 577 / 457 / 427 / 317$ & $\begin{array}{l}\text { 6,8-di-C-hexosyl } \\
\text { apigenin }\end{array}$ & Di-Glc-Api & Leaflets \\
\hline 8 & 16.8 & $239,270,335$ & $673[\mathrm{M}-\mathrm{H}]^{-}$ & $\begin{array}{l}\text { MS }^{2}[673]: 593(100), 575(10), 503(10), \\
473(15), 413(5), 383(10), 353(10) \\
\text { MS }^{2}[593]: 503(25), 473(10), 383(50), 353(100) \\
\text { MS }^{3}[673 \rightarrow 593]: 473(100), 413(20), 383(60) \\
353(100) \\
\text { MS }^{3}[673 \rightarrow 473]: 383(100), 353(100)\end{array}$ & $713\left[\mathrm{M}+\mathrm{Na}^{+}\right.$ & $\begin{array}{l}\mathrm{MS}^{2}[713]: 633(100), 593(25), \\
543(25), 513(25), 423(10), \\
393(10), 351(10) \\
\text { MS } 3513 \rightarrow 633]: 573(100), 543 \\
(100), 513(100), 483(20), 423 \\
(75), 393(20), 351(50)\end{array}$ & $\begin{array}{l}\text { 6,8-di-C-hexosyl } \\
\text { apigenin sulfate }\end{array}$ & Di-Glc-Api Sulf & Leaflets \\
\hline 9 & 17.8 & $239,270,335$ & $673[\mathrm{M}-\mathrm{H}]^{-}$ & 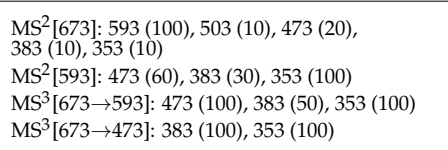 & $713[\mathrm{M}+\mathrm{K}]^{+}$ & $\begin{array}{l}\mathrm{MS}^{2}[713]: 633(100), 593(25), \\
543(25), 513(75), 483(25), 423 \\
(30), 393(30), 363(10), 351(10) \\
\mathrm{MS}^{3}[713 \rightarrow 633]: 573(20), 543 \\
(100), 513(70), 483(5), 423(50) \\
393(20), 381(50), 351(25)\end{array}$ & $\begin{array}{l}\text { 6,8-di-C-hexosyl } \\
\text { apigenin sulfate }\end{array}$ & Di-Glc-Api Sulf & Leaflets \\
\hline 10 & 21.2 & $238,272,339$ & $563[\mathrm{M}-\mathrm{H}]^{-}$ & $\mathrm{MS}^{2}[563]: 473(10), 443(30), 383(80), 353(80)$ & - & - & $\begin{array}{l}\text { 6-C-hexosyl-8-C-pentosyl } \\
\text { apigenin isomer }\end{array}$ & & Leaflets \\
\hline 11 & 22.1 & $240,270,342$ & $447[\mathrm{M}-\mathrm{H}]^{-}$ & $447 / 429 / 411 / 357 / 327 / 299$ & $449[\mathrm{M}+\mathrm{H}]^{+}$ & $449 / 413 / 383$ & $\begin{array}{l}\text { 8-C-glycosyl luteolin } \\
\text { (orientin)** }\end{array}$ & & Leaflets \\
\hline 12 & 22.3 & $238,272,339$ & $563[\mathrm{M}-\mathrm{H}]^{-}$ & $\begin{array}{l}\operatorname{MS}^{2}[563]: 503(100), 473(10), 443(20), \\
413(75), 383(50), 353(10)\end{array}$ & - & - & $\begin{array}{l}\text { 6-C-pentosyl-8-C-hexosyl } \\
\text { apigenin isomer }\end{array}$ & & Leaflets \\
\hline 13 & 22.9 & $241,270,346$ & $447[\mathrm{M}-\mathrm{H}]^{-}$ & $447 / 429 / 411 / 357 / 327 / 299$ & $449[\mathrm{M}+\mathrm{H}]^{+}$ & 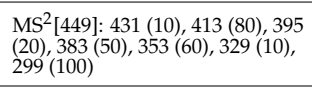 & $\begin{array}{l}\text { 6-C-glycosyl luteolin } \\
\text { (isoorientin)* }\end{array}$ & & Leaflets \\
\hline 14 & 23.2 & $238,272,340$ & $563[\mathrm{M}-\mathrm{H}]^{-}$ & $\mathrm{MS}^{2}[563]: 473(75), 443(75), 383$ (25), 353 (100) & - & - & $\begin{array}{l}\text { 6-C-hexosyl-8-C-pentosyl } \\
\text { apigenin isomer }\end{array}$ & & Leaflets \\
\hline 15 & 24.9 & $241,271,336$ & $563[\mathrm{M}-\mathrm{H}]^{-}$ & $\mathrm{MS}^{2}[563]: 443$ (100), 383 (30), 353 (50), $323(20)$ & - & - & $\begin{array}{l}\text { 6-C-hexosyl-8-C-pentosyl } \\
\text { apigenin isomer }\end{array}$ & & Leaflets \\
\hline 16 & 25.6 & $238,277,335$ & $563[\mathrm{M}-\mathrm{H}]^{-}$ & $\mathrm{MS}^{2}[563]: 503(25), 473(10), 383$ (10), 353 (100) & - & - & $\begin{array}{l}\text { 6-C-pentosyl-8-C-hexosyl } \\
\text { apigenin isomer }\end{array}$ & & Leaflets \\
\hline 17 & 26.4 & $241,270,337$ & $431[\mathrm{M}-\mathrm{H}]^{-}$ & $431 / 413 / 395 / 341 / 311 / 283$ & $433[\mathrm{M}+\mathrm{H}]^{+}$ & $\begin{array}{l}\text { MS }^{2}[4333]: 397(75), 379(30), 367 \\
(100), 337(50), 313(40), 295(20), \\
283(50)\end{array}$ & $\begin{array}{l}\text { 6-C-glycosyl apigenin } \\
\text { (isovitexin)* }\end{array}$ & & Leaflets \\
\hline
\end{tabular}

* Structure confirmed using standard compounds. 


\subsubsection{Characterization of Luteolin Derivatives $(\mathrm{Mr}=448)$}

Compounds 11 and $13(\mathrm{Mr}=432)$ gave $[\mathrm{M}-\mathrm{H}]^{-}$at $m / z 447$ and $[\mathrm{M}+\mathrm{H}]^{+}$at $m / z 449$. Characteristics losses of $90 \mathrm{Da}$ and $120 \mathrm{Da}$ were diagnostics of hexose residues. The fragments ions at $m / z 327$ (aglycone +42 ) and $m / z 357$ (aglycone +72 ) in the negative mode clearly indicated $C$-glycosyl luteolin derivatives [25]. Based on retention order and injection of synthetic standards, $\mathbf{1 1}$ was identified as 8-C-glycosyl luteolin and $\mathbf{1 3}$ as 6-C-glycosyl luteolin.

\subsubsection{Quantification of Chemical Compounds in Root and Leaflet Extracts}

Root extracts of E. oleracea were mainly characterized by the presence of hydroxycinnamic acids HCA, namely three caffeoylquinic acids (CQA) and three caffeoylshikimic acids (CSA) (Figure 4). Hydroxycinnamic acids are known to display biological properties such as antiviral, anti-inflammatory and antioxidant activity [27]. They also play important physiological role of defense against pathogens and disease resistance [27], which is essential for vulnerable vegetative organs such as roots. The CSA content was higher than the CQA content in the root extracts, $(2.5 \mathrm{mg} / \mathrm{g}$ DM against $0.5 \mathrm{mg} / \mathrm{g}$ DM for the most concentrated extract), i.e., $70 \%-85 \%$ of all HCA (Figure 4). 5-CQA was the major compound amongst CQA, while each of the three CSA was found in almost similar amounts. The qualitative composition of E. oleracea roots was similar to that of O. bataua and O. bacaba [12]. However, the quantitative compositions of $O$. bacaba were different with a global two-fold lower content in compound compared to E. oleracea.

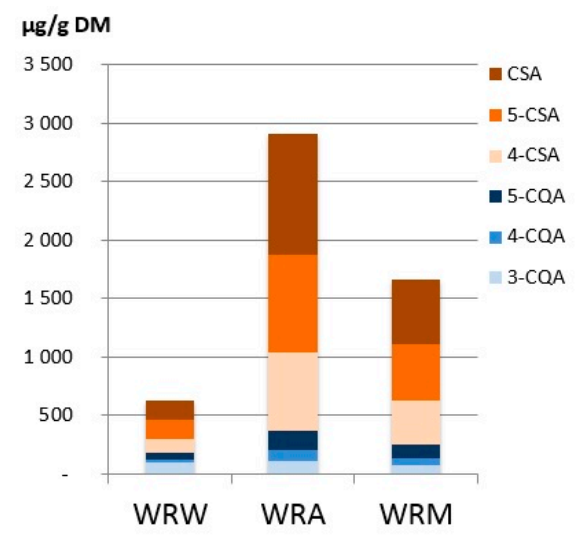

(a)

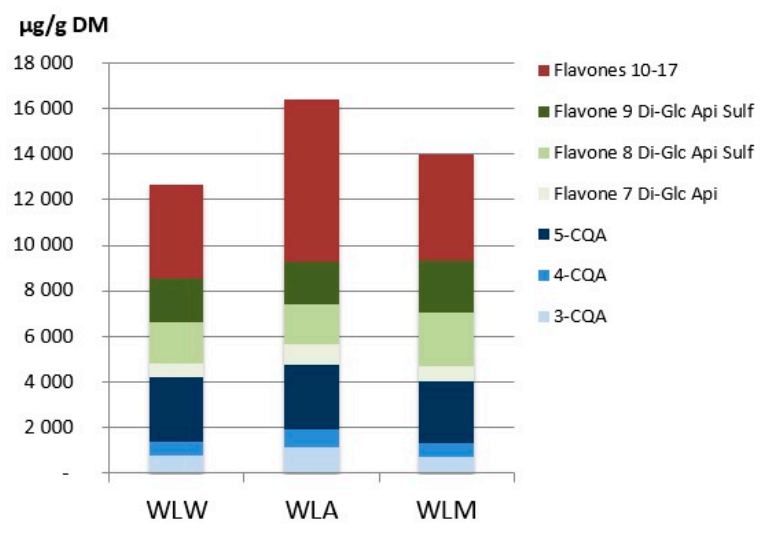

(b)

Figure 4. Chemical composition of: (a) root extracts; and (b) leaflet extracts of Euterpe oleracea; W: Wassaye (E. oleracea); R: roots; L: leaflets; W: water; A: acetone/water 70/30; M: methanol/water 70/30; CQA: caffeoylquinic acid; CSA: caffeoylshikimic acid (for identification of compounds 7-17, see Table 2); Di-Glc-Api: 6,8-di-C-hexosyl apigenin; Di-Glc-Api Sulf: 6,8-di-C-hexosyl apigenin sulfate; $n=3$ biological replicates.

Leaflet extracts were characterized by two main compound families: three caffeoylquinic acids, as in the root extracts, and eleven flavones (Figure 4). 5-CQA was the main CQA in the leaflet extracts ( $40 \%-70 \%$ of total CQA). Higher contents of CQA (up to $4.5 \mathrm{mg} / \mathrm{g} \mathrm{DM}$ ) were found in the leaflet extracts compared to the root extracts. Leaflet flavones were quantified mainly as $C$-monoglycosyl and $C$-diglycosyl derivatives of apigenin, and to a lesser extent as $C$-glycosyl derivatives of luteolin. Di-C-glycosyl derivatives of apigenin (compounds 7-9) were the major compounds in leaflet extracts of E. oleracea, accounting for almost $50 \%$ of all C-glycosylflavones, the sulfated flavones 8 and 9 being the major ones with about $2 \mathrm{mg} / \mathrm{g}$ DM. Apigenin $C$-glycosides are phytochemical markers specific to a few Arecaceae species, while $C$-glycosyl luteolin derivatives are more common amongst palm tree species [28]. More recently, C-glycosyl derivatives of apigenin, close to those found in this work, were identified in another Amazonian palm tree species, Mauritia flexuosa [29]. The presence of sulfated 
flavones in the leaflet extracts of E. oleracea is interesting as natural sulfated flavonoids inspire the design of smaller bioactive compounds with sulfate groups [30]. E. oleracea leaflets composition was qualitatively similar to that of Oenocarpus leaflets [12] but the quantitative composition was conspicuously different (maximum 1500 and $5000 \mu \mathrm{g} / \mathrm{g}$ DM for O. bataua and O. bacaba, respectively, against $16000 \mathrm{\mu g} / \mathrm{g}$ DM for E. oleracea). It was interesting to observe that these three palm tree species (E. oleracea, O. bacaba and O. bataua) have the same qualitative composition of their roots or of their leaflets but have quite different antioxidant activities. Indeed, E. oleracea leaflets were two fold more active than $O$. bacaba and $O$. bataua leaflets. The difference of activity could come from the quantity of polyphenolic compounds in the extracts, rather than the qualitative composition. These results interrogate the fact that there might be a particular regulation of key enzymes in the biosynthetic pathway of polyphenols in E. oleracea leaflets. To validate this hypothesis, numerous molecular and biochemical studies will be required.

\subsection{Relationship between the Chemical Composition and the Antioxidant Activity}

Principal Component Analysis (PCA) was carried out using the data from the chemical antioxidant assays (DPPH, FRAP, ORAC) and the quantification of compounds in root and leaflet extracts of E. oleracea. The antioxidant activity of the roots was linked to the CSA and CQA contents (negative side of PC1) (Figure 5). There was no clear differentiation of the methanol and acetone root extracts according to the PCA, as they had very similar antioxidant activity and chemical composition.

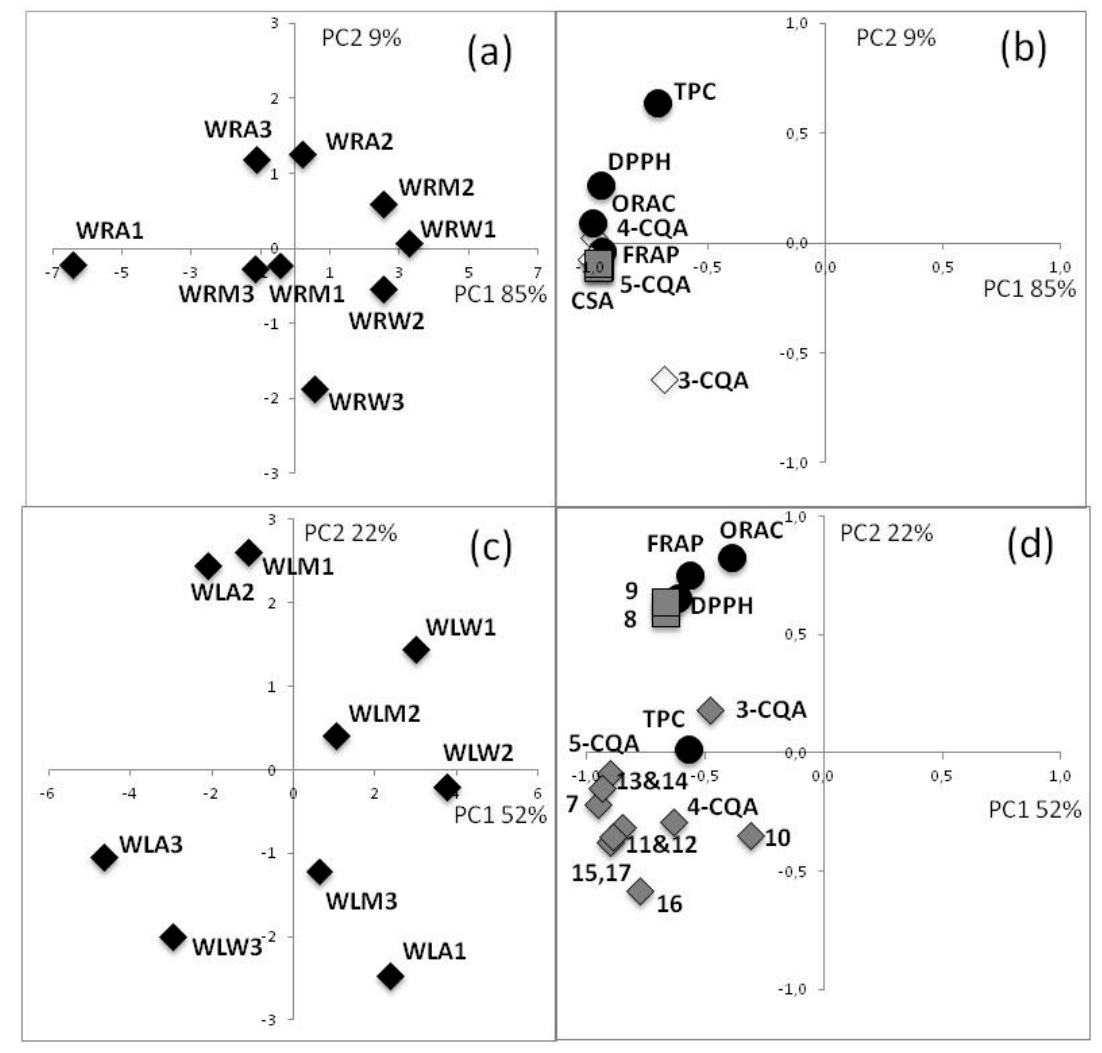

Figure 5. Principal Component Analysis (PCA) plots for antioxidant activity and chemical composition of: root extracts $(\mathbf{a}, \mathbf{b})$; and leaflet extracts $(\mathbf{c}, \mathbf{d})$ of Euterpe oleracea; W: Wassaye (E. oleracea); R: roots; L: leaflets; W: water; A: acetone/water: 70/30; M: methanol/water: 70/30; CQA: caffeoylquinic acid; CSA: caffeoylshikimic acid, (for identification of compounds $\mathbf{7 - 1 7}$, see Table 2); DPPH: 2,2-Diphenyl-1-picrylhydrazyl; FRAP: ferric reducing antioxidant power; ORAC: oxygen radical absorbance capacity. 
For the leaflet extracts, the most active extracts in all the chemical assays were on the positive side of PC2, which was correlated with high contents of flavones 8 and $\mathbf{9}$ (Figure 5). These results translated quite well to the CAA assay, where the leaflet extracts of E. oleracea were very active. The PCA highlighted a correlation between the antioxidant activity of $E$. oleracea leaflet extracts and the presence of di-C-glycosyl apigenin sulfates (8 and $\mathbf{9})$. Indeed, hydroxyl substituted flavones such as apigenin or luteolin derivatives are known to have high antioxidant activity due to their structures [31].

\section{Materials and Methods}

\subsection{Chemicals and Reagents}

Solvents used for extraction and LC-MS analysis were of HPLC grade, obtained from Carlo Erba Reagents (Val de Reuil, France). Standards of 5-O-caffeoylquinic acid, orientin ( $>99 \%$ ), isoorientin $(>99 \%)$, and isovitexin (>99\%) were obtained from Extrasynthèse (Genay, France). Gallic acid-1-hydrate (99\%) was purchased from Panreac Quimica (Barcelona, Spain).

\subsection{Plant Materials}

Roots and leaflets of three specimens of E. oleracea were harvested on February 2013, in Macouria, French Guiana. Samples were washed, cut, freeze-dried and grinded immediately after collection. Dried matter was then stored at $-20{ }^{\circ} \mathrm{C}$ to limit degradation until extraction.

\subsection{Extraction}

Extractions were performed following the method previously published [12]. Three solvents were used for extraction of roots and leaflets from E. oleracea and green tea leaves: water (W), methanol/water $70 / 30 v / v(\mathrm{M})$ and acetone/water 70/30 $v / v(\mathrm{~A})$. The combination of acetone or methanol with water is commonly used to extract polyphenols [32]. Ultrasounds were used to assist the extraction of polyphenols of leaflets and roots from E. oleracea, as they are known to be a green alternative to conventional extraction methods and give optimized extraction efficiency and reduced extraction time [33]. Preliminary studies using ultrasound extraction were carried out to determine that four successive extractions gave optimized extraction efficiency.

\subsection{Total Phenolics by Folin-Ciocalteu}

Total Phenolic Content (TPC) was determined using the Folin-Ciocalteu method as previously described [12].

\subsection{Chemical Antioxidant Assays (DPPH, FRAP, ORAC)}

Chemical antioxidant properties were assessed using DPPH, FRAP and ORAC assays as described in our previous paper [12]. These assays are based on different antioxidant mode of action like electron transfer (FRAP), hydrogen transfer (ORAC) or a mixed mechanism implying both electron and hydrogen transfer (DPPH) [13].

\subsection{Cellular Assay}

\subsubsection{Cell Culture}

Normal Human Dermal Fibroblasts (NHDF) were purchased from PromoCell (Heidelberg, Germany), cultured in growth medium RPMI GlutaMAX ${ }^{\mathrm{TM}}$ (89\%) (Thermo Fischer Scientific, Waltham, MA, USA), supplemented with 5\% FBS (Fetal Bovine Serum), $1 \%$ antibiotics, $5 \% \mathrm{CO}_{2}$ and maintained at $37^{\circ} \mathrm{C}$. NHDF cells were used to determine the cytotoxicity of E. oleracea extracts and to assess the antioxidant activity of the extracts in a cell-based assay described in Section 3.6.3. 


\subsubsection{Cytotoxicity Assay}

Cytotoxicity of the extracts in NHDF was measured using the MTT (3-(4,5-dimethylthiazol-2 -yl)-2,5-diphenyltetrazolium bromide) method [34]. NHDF cells were incubated for $24 \mathrm{~h}$ at $37^{\circ} \mathrm{C}$, in presence or absence of E. oleracea extracts at 100,200,300, 400 and $500 \mu \mathrm{g} / \mathrm{mL}$. The cells were washed twice with $500 \mu \mathrm{L}$ of a phosphate buffer solution (PBS), then incubated at $37^{\circ} \mathrm{C}$ for $3 \mathrm{~h}$ with MTT at $0.5 \mathrm{mg} / \mathrm{mL}$. MTT was removed using $1 \mathrm{~mL}$ of DMSO and the plate was kept in the dark at room temperature during $30 \mathrm{~min}$ before recording the absorbance at $595 \mathrm{~nm}$ using a plate-reader (Dynex, Magellan Biosciences, Tampa, FL, USA) to detect viable cells. A decrease of the absorbance by more than $20 \%$ was set as the limit for cytotoxicity.

\subsubsection{Cellular Antioxidant Activity (CAA) Assay}

The cell-based assay was done according to the method of Wolfe and Liu [35], with some modifications. Briefly, NHDF cells were seeded for $24 \mathrm{~h}$ on a 96-well microplate at a density of $11 \times 10^{4}$ cells by well in $100 \mu \mathrm{L}$ of RPMI growth medium. The growth medium was removed and the wells were washed with PBS. Wells were treated in triplicates with $100 \mu \mathrm{L}$ of extracts at four concentrations $(10,25,50$ and $100 \mu \mathrm{g} / \mathrm{mL})$, not cytotoxic to the NHDF cells, plus $50 \mu \mathrm{M}$ $2^{\prime}, 7^{\prime}$-dichlorodihydrofluorescein diacetate (DCFH-DA) dissolved in the treatment medium and kept in the dark for $1 \mathrm{~h}$. Control wells (cells treated with $50 \mu \mathrm{M}$ of DCFH-DA, without extract), and blank wells (cells treated only with growth medium) were included. Then, the wells were drained from the treatment medium and $100 \mu \mathrm{L}$ of 2,2'-Azobis(2-amidinopropane) dihydrochloride (AAPH) at $250 \mu \mathrm{M}$ was added in each well (except in blank wells). Immediately after the AAPH addition, the plate was placed into a plate-reader (Dynex, Magellan Biosciences) at $37^{\circ} \mathrm{C}$ and the fluorescence was recorded for $30 \mathrm{~min}$ ( $\lambda_{\text {excitation }} 485 \mathrm{~nm}, \lambda_{\text {emission }} 538 \mathrm{~nm}$ ). After blank subtraction from the fluorescence readings, the area under the curve of fluorescence versus time was integrated to calculate the CAA value at each extracts concentration tested as follows: CAA unit: $100-\left(\int \mathrm{SA} / \int \mathrm{CA}\right) \times 100$ where $\int \mathrm{SA}$ is the integrated area under the sample fluorescence versus time curve and $\int C A$ is the integrated area from the control curve. The median effective concentration $\mathrm{EC}_{50}(\mu \mathrm{g} / \mathrm{mL})$, was determined for E. oleracea extracts from the median effect plot of $\log (f a / f u)$ versus $\log$ (concentration), where $f a$ is the fraction affected and $f u$ is the fraction unaffected by the treatment. Quercetin was used as a standard in the CAA assay and the cellular antioxidant activity of E. oleracea extracts was then expressed in $\mu \mathrm{mol}$ Quercetin equivalents/g of dried matter ( $\mu \mathrm{mol} \mathrm{QEq} / \mathrm{g} \mathrm{DM})$.

\subsubsection{DNA Nicking Assay}

The DNA nicking assay was performed using the pUC18 plasmid. All conditions required to analyze aqueous and organic extracts were previously optimized [16]. Four microliters of E. oleracea extracts (max $7 \%$ acetone) at various concentrations were added to $4 \mu \mathrm{L}$ of the Fenton reaction mixture, containing: plasmid DNA $(150 \mu \mathrm{g} / \mu \mathrm{L})$, phosphate buffer $(50 \mathrm{mM}, \mathrm{pH} 7.4), \mathrm{H}_{2} \mathrm{O}_{2}(30 \mathrm{mM}), \mathrm{FeSO}_{4}$ $(2 \mathrm{mM} / 8 \mathrm{mM})$ and EDTA-Na $2(3.75 \mathrm{mM} / 15 \mathrm{mM})$ for aqueous and acetone extracts respectively. The final volume was adjusted to $24 \mu \mathrm{L}$ using distilled water and incubated for $20 \mathrm{~min}$ and $15 \mathrm{~min}$ at $37^{\circ} \mathrm{C}$ for aqueous and acetone extracts respectively. Two microliters of loading dye was added to the incubated mixture, and $10 \mu \mathrm{L}$ were loaded onto $1 \%(w / v)$ agarose gel. After electrophoresis in TAE buffer (0.04 M tris-acetate and 1 mM EDTA, pH 7.4) using a DNA subcell (Bio-Rad Laboratories, Hercules, CA, USA), the agarose gel was stained with ethidium bromide for $15 \mathrm{~min}$ and DNA bands were analyzed using a Bio-Rad Gel Doc ${ }^{\mathrm{TM}} \mathrm{XR}$ (Bio-Rad Laboratories). The prooxidant and antioxidant activity of the extracts was assessed using band intensity (NIH Image J) of form I (supercoiled DNA) and form III (nicked linear DNA) compared to the appropriate controls. DNA incubated with and without Fenton's reagent was used as positive and negative control, respectively. Trolox was used as a control of DNA protection, at a concentration of 0.01 and $0.1 \mathrm{mg} / \mathrm{mL}$ for aqueous and acetone extracts, respectively. 


\subsubsection{Analysis by LC-MS/MS}

LC-MS/MS analysis was performed on an ion trap (500-MS Varian, Palo Alto, CA, USA) equipped with an electrospray ionization source and coupled to a Pro Star LC system (Agilent Technologies, Santa Clara, CA, USA) and a Pro Star 335 PDA (Agilent). Extracts were filtered using $0.2 \mu \mathrm{m}$ PTFE filters. Twenty microliters of samples were injected onto a Kinetex PFP column, $100 \times 4.6 \mathrm{~mm}, 2.6 \mu \mathrm{m}$ (Agilent) using a gradient of $1 \%$ formic acid (A) and acetonitrile (B) at $25{ }^{\circ} \mathrm{C}$. The gradient was as follows: $5 \%-10 \%$ B in $10 \mathrm{~min}, 10 \%-20 \%$ in $10 \mathrm{~min}, 20 \%$ held for $10 \mathrm{~min}, 20 \%-100 \%$ in $5 \mathrm{~min}, 100 \%$ held for $5 \mathrm{~min}$, and returned to initial conditions for $9 \mathrm{~min}$ to reequilibrate the column. The flow rate was $1 \mathrm{~mL} / \mathrm{min}$. The total run time per sample was $60 \mathrm{~min}$.

Analyses were first performed using Full scan mode $(m / z$ 120-750), both in negative mode and positive mode to identify the molecular ions and then in TurboDDS ${ }^{\mathrm{TM}}$ mode (Data Dependent Scanning, Varian) to acquire $\mathrm{MS}^{2}$ spectra. Helium was used as the damping and collision gas at $0.8 \mathrm{~mL} / \mathrm{min}$. The operation parameters were as follows: nebulizer gas pressure $50 \mathrm{psi}$, drying gas pressure $25 \mathrm{psi}$, drying gas temperature $350{ }^{\circ} \mathrm{C}$, needle voltage $-5000 \mathrm{~V} / 5000 \mathrm{~V}$, sprayshield voltage $-600 \mathrm{~V}$, spray chamber $50{ }^{\circ} \mathrm{C}$, capillary voltage $100 \mathrm{~V} /-70 \mathrm{~V}$ (negative ionization mode/positive ionization mode).

The identification of compounds was performed according to their $\mathrm{MS}^{2}$ fragmentation [15-17,26,27], using standards when available. Quantification was carried out with UV detection. 5-CQA and 6-C-glycosyl apigenin (isovitexin) were used as calibration standards $\left(\lambda_{\max }=320 \mathrm{~nm}\right.$ ) to quantify hydroxycinnamic acids (caffeoylquinic acids-CQA and caffeoylshikimic acids-CSA) and flavones, respectively. Gallic acid was used as the internal standard at $\lambda_{\max }=280 \mathrm{~nm}$.

\subsubsection{Statistical Data Analysis}

Results of antioxidant activity were presented as the mean of three biological replicates and standard error (SE) or standard error of the mean (SEM). Comparisons between extracts in the TPC, ORAC, FRAP, DPPH and DNA nicking assays were performed using an ANOVA followed by multiple comparisons using Fisher's Least Significant Difference test $(p<0.05)$. Principal component analysis (PCA) was performed on the phytochemical composition and chemical antioxidant activity (DPPH, FRAP, and ORAC) of roots and leaflet extracts from E. oleracea using the Statistica program (Statsoft, Paris, France).

\section{Conclusions}

Root and leaflet extracts from E. oleracea were active across the board in different chemical antioxidant assays (DPPH, FRAP, ORAC, DNA nicking) and biological assay (CAA). The high antioxidant activity of the root and leaflet extracts of E. oleracea was respectively correlated to the presence of hydroxycinnamic acids and apigenin $C$-glycosides. The high antioxidant activity of E. oleracea leaflets seemed to come from their highest content of polyphenols, suggesting a particular regulation of the polyphenols biosynthetic pathway. This study shows for the first time that Euterpe oleracea roots and leaflets, which are currently by-products of the palm heart industry, could, along with the berries, be valorized as a new non-cytotoxic source of antioxidants containing hydroxycinnamic acids and flavonoids for pharmaceutical, nutraceutical or cosmetic applications.

Supplementary Materials: Supplementary materials can be found at www.mdpi.com/1422-0067/18/1/61/s1.

Acknowledgments: We thank the European Regional Development Fund (ERDF/FEDER, presage 30574), "la Région Guyane" (French Guiana Region), the French Ministry of Higher Education and Research (MESR) and the "Centre National d'Etudes Spatiales" (CNES) for financial support of this research project (Palmazon Project, Valorization of Amazonian palm trees from French Guiana, 2010). The University of French Guiana is gratefully acknowledged for support. We also thank Mathew Njoroge from the University of Cape Town, for his work in proof reading this manuscript. 
Author Contributions: Christel Brunschwig performed the ORAC assay, identified and quantified the compounds by LC-MS/MS, performed statistical analysis, and wrote the manuscript; Louis-Jérôme Leba performed the extractions, the DPPH assay, the Folin-Ciocalteu assay, performed statistical analysis, and wrote the manuscript; Mona Saout and Karine Martial helped in performing the experiments; Didier Bereau managed, edited and revised the manuscript; and Jean-Charles Robinson managed, designed and revised the manuscript. The final version of the manuscript has been read and accepted by all the authors.

Conflicts of Interest: The authors declare no conflict of interest.

\section{Abbreviations}

$\begin{array}{ll}\text { DPPH } & \text { 2,2-Diphenyl-1-picrylhydrazyl } \\ \text { FRAP } & \text { Ferric Reducing Antioxidant Power } \\ \text { ORAC } & \text { Oxygen Radical Absorbance Capacity } \\ \text { CAA } & \text { Cellular Antioxidant Activity } \\ \text { TPC } & \text { Total Polyphenol Content } \\ \text { GAEq } & \text { Gallic acid equivalent } \\ \text { TEq } & \text { Trolox equivalent } \\ \text { QEq } & \text { Quercetin equivalent } \\ \text { DM } & \text { Dry Matter } \\ \text { PCA } & \text { Principal Component Analysis } \\ \text { NHDF } & \text { Normal Human Dermal Fibroblasts } \\ \text { HCA } & \text { Hydroxycinnamic acid } \\ \text { CQA } & \text { Caffeoylquinic acid } \\ \text { CSA } & \text { Caffeoylshikimic acid } \\ \text { MTT } & \text { 3-(4,5-Dimethylthiazol-2-yl)-2,5-diphenyltetrazolium bromide }\end{array}$

\section{References}

1. Yamaguchi, K.K.D.L.; Pereira, L.F.R.; Lamarão, C.V.; Lima, E.S.; da Veiga, V.F., Jr. Amazon açai: Chemistry and biological activities: A review. Food Chem. 2015, 179, 137-151. [CrossRef] [PubMed]

2. Heinrich, M.; Dhanji, T.; Casselman, I. Açai (Euterpe oleracea Mart.) -A phytochemical and pharmacological assessment of the species' health claims. Phytochem. Lett. 2011, 4, 10-21. [CrossRef]

3. Grenand, P.; Moretti, C.; Jacquemin, H.; Prévost, M.-F. Pharmacopées traditionnelles en Guyane; IRD Editions: Paris, France, 2004.

4. Bourdy, G.; deWalt, S.J.; Chávez de Michel, L.R.; Roca, A.; Deharo, E.; Muñoz, V.; Balderrama, L.; Quenevo, C.; Gimenez, A. Medicinal plants uses of the Tacana, an Amazonian Bolivian ethnic group. J. Ethnopharmacol. 2000, 70, 87-109. [CrossRef]

5. Hajdu, Z.; Hohmann, J. An ethnopharmacological survey of the traditional medicine utilized in the community of Porvenir, Bajo Paraguá Indian Reservation, Bolivia. J. Ethnopharmacol. 2012, 139, 838-857. [CrossRef] [PubMed]

6. Deharo, E.; Baelmans, R.; Gimenez, A.; Quenevo, C.; Bourdy, G. In vitro immunomodulatory activity of plants used by the Tacana ethnic group in Bolivia. Phytomedicine 2004, 11, 516-522. [CrossRef] [PubMed]

7. Galotta, A.L.Q.A.; Boaventura, M.A.D.; Lima, L.A.R.S. Antioxidant and cytotoxic activities of "Açaí" (Euterpe precatoria mart.). Quim. Nova 2008, 31, 1427-1430. [CrossRef]

8. Schieber, A.; Stintzing, F.; Carle, R. By-products of plant food processing as a source of functional compounds-recent developments. Trends Food Sci. Technol. 2001, 12, 401-413. [CrossRef]

9. Ferlemi, A.-V.; Lamari, F.N. Berry Leaves: An Alternative Source of Bioactive Natural Products of Nutritional and Medicinal Value. Antioxidants 2016, 5, 17. [CrossRef] [PubMed]

10. Barros, L.; Calhelha, R.C.; Queiroz, M.J.R.P.; Santos-Buelga, C.; Santos, E.A.; Regis, W.C.B.; Ferreira, I.C.F.R. The powerful in vitro bioactivity of Euterpe oleracea Mart. seeds and related phenolic compounds. Ind. Crops Prod. 2015, 76, 318-322. [CrossRef]

11. Sudo, R.T.; Neto, M.L.; Monteiro, C.E.S.; Amaral, R.V.; Resende, A.C.; Souza, P.J.C.; Zapata-Sudo, G.; Moura, R. Antinociceptive effects of hydroalcoholic extract from Euterpe oleracea Mart. (Açaí) in a rodent model of acute and neuropathic pain. BMC Complement. Altern. Med. 2015, 15, 208. [CrossRef] [PubMed] 
12. Leba, L.-J.; Brunschwig, C.; Saout, M.; Martial, K.; Bereau, D.; Robinson, J.-C. Oenocarpus bacaba and Oenocarpus bataua Leaflets and Roots: A New Source of Antioxidant Compounds. Int. J. Mol. Sci. 2016, 17, 1014. [CrossRef] [PubMed]

13. Prior, R.L.; Wu, X.; Schaich, K. Standardized methods for the determination of antioxidant capacity and phenolics in foods and dietary supplements. J. Agric. Food Chem. 2005, 53, 4290-4302. [CrossRef] [PubMed]

14. Rezaire, A.; Robinson, J.-C.; Bereau, D.; Verbaere, A.; Sommerer, N.; Khan, M.K.; Durand, P.; Prost, E.; Fils-Lycaon, B. Amazonian palm Oenocarpus bataua ("patawa"): Chemical and biological antioxidant activity-Phytochemical composition. Food Chem. 2014, 149, 62-70. [CrossRef] [PubMed]

15. Abadio Finco, F.D.B.; Kammerer, D.R.; Carle, R.; Tseng, W.-H.; Böser, S.; Graeve, L. Antioxidant activity and characterization of phenolic compounds from bacaba (Oenocarpus bacaba Mart.) fruit by HPLC-DAD-MS(n). J. Agric. Food Chem. 2012, 60, 7665-7673. [CrossRef] [PubMed]

16. Leba, L.-J.; Brunschwig, C.; Saout, M.; Martial, K.; Vulcain, E.; Bereau, D.; Robinson, J.-C. Optimization of a DNA nicking assay to evaluate Oenocarpus bataua and Camellia sinensis antioxidant capacity. Int. J. Mol. Sci. 2014, 15, 18023-18039. [CrossRef] [PubMed]

17. Tiveron, A.P.; Melo, P.S.; Bergamaschi, K.B.; Vieira, T.M.F.S.; Regitano-d'Arce, M.A.B.; Alencar, S.M. Antioxidant activity of Brazilian vegetables and its relation with phenolic composition. Int. J. Mol. Sci. 2012, 13, 8943-8957. [CrossRef] [PubMed]

18. Girard-Lalancette, K.; Pichette, A.; Legault, J. Sensitive cell-based assay using DCFH oxidation for the determination of pro- and antioxidant properties of compounds and mixtures: Analysis of fruit and vegetable juices. Food Chem. 2009, 115, 720-726. [CrossRef]

19. Fang, N.; Yu, S.; Prior, R.L. LC/MS/MS characterization of phenolic constituents in dried plums. J. Agric. Food Chem. 2002, 50, 3579-3585. [CrossRef] [PubMed]

20. Clifford, M.N.; Johnston, K.L.; Knight, S.; Kuhnert, N. Hierarchical scheme for LC-MSn identification of chlorogenic acids. J. Agric. Food Chem. 2003, 51, 2900-2911. [CrossRef] [PubMed]

21. Regos, I.; Treutter, D. Optimization of a high-performance liquid chromatography method for the analysis of complex polyphenol mixtures and application for sainfoin extracts (Onobrychis viciifolia). J. Chromatogr. A 2010, 1217, 6169-6177. [CrossRef] [PubMed]

22. Hammouda, H.; Kalthoum Chérif, J.; Trabelsi-Ayadi, M.; Baron, A.; Guyot, S. Detailed polyphenol and tannin composition and its variability in Tunisian dates (Phoenix dactylifera L.) at different maturity stages. J. Agric. Food Chem. 2013, 61, 3252-3263. [CrossRef] [PubMed]

23. Jaiswal, R.; Sovdat, T.; Vivan, F.; Kuhnert, N. Profiling and characterization by LC-MSn of the chlorogenic acids and hydroxycinnamoylshikimate esters in maté (Ilex paraguariensis). J. Agric. Food Chem. 2010, 58, 5471-5484. [CrossRef] [PubMed]

24. Parveen, I.; Threadgill, M.D.; Hauck, B.; Donnison, I.; Winters, A. Isolation, identification and quantitation of hydroxycinnamic acid conjugates, potential platform chemicals, in the leaves and stems of Miscanthus $\times$ giganteus using LC-ESI-MS(n). Phytochemistry 2011, 72, 2376-2384. [CrossRef] [PubMed]

25. Ferreres, F.; Silva, B.M.; Andrade, P.B.; Seabra, R.M.; Ferreira, M.A. Approach to the study of C-glycosyl flavones by ion trap HPLC-PAD-ESI/MS/MS: Application to seeds of quince (Cydonia oblonga). Phytochem. Anal. 2003, 14, 352-359. [CrossRef] [PubMed]

26. Barron, D.; Varin, L.; Ibrahim, R.K.; Harborne, J.B.; Williams, C.A. Sulphated flavonoids-an update. Phytochemistry 1988, 27, 2375-2395. [CrossRef]

27. Karaköse, H.; Jaiswal, R.; Kuhnert, N. Characterization and quantification of hydroxycinnamate derivatives in Stevia rebaudiana leaves by LC-MS(n). J. Agric. Food Chem. 2011, 59, 10143-10150. [CrossRef] [PubMed]

28. Williams, C.A.; Harborne, J.B.; Clifford, H.T. Negatively charged flavones and tricin as chemosystematic markers in the palmae. Phytochemistry 1973, 12, 2417-2430. [CrossRef]

29. De Oliveira, D.M.; Siqueira, E.P.; Nunes, Y.R.F.; Cota, B.B. Flavonoids from leaves of Mauritia flexuosa. Braz. J. Pharmacogn. 2013, 23, 614-620. [CrossRef]

30. Correia-da-Silva, M.; Sousa, E.; Pinto, M.M.M. Emerging sulfated flavonoids and other polyphenols as drugs: Nature as an inspiration. Med. Res. Rev. 2014, 34, 223-279. [CrossRef] [PubMed]

31. Heim, K.E.; Tagliaferro, A.R.; Bobilya, D.J. Flavonoid antioxidants: Chemistry, metabolism and structure-activity relationships. J. Nutr. Biochem. 2002, 13, 572-584. [CrossRef] 
32. Ignat, I.; Volf, I.; Popa, V.I. A critical review of methods for characterisation of polyphenolic compounds in Fruits and Vegetables. Food Chem. 2011, 126, 1821-1835. [CrossRef] [PubMed]

33. Barba, F.J.; Zhu, Z.; Koubaa, M.; Sant'Ana, A.S.; Orlien, V. Green alternative methods for the extraction of antioxidant bioactive compounds from winery wastes and by-products: A review. Trends Food Sci. Tech. 2016, 46, 96-109. [CrossRef]

34. Mosmann, T. Rapid colorimetric assay for cellular growth and survival: Application to proliferation and cytotoxicity assays. J. Immunol. Methods 1983, 65, 55-63. [CrossRef]

35. Wolfe, K.L.; Rui, H.L. Cellular antioxidant activity (CAA) assay for assessing antioxidants, foods, and dietary supplements. J. Agric. Food Chem. 2007, 55, 8896-8907. [CrossRef] [PubMed]

(C) 2016 by the authors; licensee MDPI, Basel, Switzerland. This article is an open access article distributed under the terms and conditions of the Creative Commons Attribution (CC-BY) license (http://creativecommons.org/licenses/by/4.0/). 